\title{
Native state stabilization by NSAIDs inhibits transthyretin amyloidogenesis from the most common familial disease variants
}

\author{
Sean R Miller, Yoshiki Sekijima and Jeffery W Kelly \\ Department of Chemistry and The Skaggs Institute of Chemical Biology, The Scripps Research Institute, \\ La Jolla, CA 92037, USA
}

\begin{abstract}
Transthyretin (TTR) tetramer dissociation and misfolding affords a monomeric amyloidogenic intermediate that misassembles into aggregates including amyloid fibrils. Amyloidogenesis of wild-type (WT) TTR causes senile systemic amyloidosis (SSA), whereas fibril formation from one of the more than 80 TTR variants leads to familial amyloidosis, typically with earlier onset than SSA. Several nonsteroidal anti-inflammatory drugs (NSAIDs) stabilize the native tetramer, strongly inhibiting TTR amyloid fibril formation in vitro. Structure-based designed NSAID analogs are even more potent amyloid inhibitors. The effectiveness of several NSAIDs, including diclofenac, diflunisal, and flufenamic acid, as well as the diclofenac analog, 2-[(3,5-dichlorophenyl) amino] benzoic acid (inhibitor 1), has been demonstrated against WT TTR amyloidogenesis. Herein, the efficacy of these compounds at preventing acid-induced fibril formation and urea-induced tetramer dissociation of the most common disease-associated TTR variants (V30M, V122I, T60A, L58H, and I84S) was evaluated. Homotetramers of these variants were employed for the studies within, realizing that the tetramers in compound heterozygote patients are normally composed of a mixture of WT and variant subunits. The most common familial TTR variants were stabilized substantially by flufenamic acid and inhibitor 1 , and to a lesser extent by diflunisal, against acid-mediated fibril formation and chaotrope denaturation, suggesting that this chemotherapeutic option is viable for patients with familial transthyretin amyloidosis.
\end{abstract}

Laboratory Investigation (2004) 84, 545-552, advance online publication, 16 February 2004; doi:10.1038/labinvest.3700059

Keywords: transthyretin; NSAIDs; amyloidosis; familial amyloid polyneuropathy; native state stabilization

The amyloidoses are a large group of postsecretory protein misfolding diseases wherein a peptide or protein misassembles into aggregates of varying morphology in the extracellular spaces. These aggregates include amyloid fibrils having a cross $\beta$-sheet structure. The pathology of these diseases seems to be orchestrated by soluble diffusible precursors of amyloid fibrils through direct toxicity, through disruption of cellular function, or through the mediation of chronic inflammation. ${ }^{1-3}$ The conversion of a folded protein to amyloid fibrils generally requires partial unfolding facilitated by a mutation in the protein, a change in environment, or both. ${ }^{4-8}$

Transthyretin (TTR), a tetrameric protein composed of identical subunits, transports thyroxine

Correspondence: JW Kelly, Department of Chemistry and The Skaggs Institute of Chemical Biology, The Scripps Research Institute, BCC506, 10550 N. Torrey Pines Rd., La Jolla, CA 92037. E-mail: jkelly@scripps.edu

Received 29 October 2003; revised 12 December 2003; accepted 14 December 2003; published online 16 February 2004 and the retinol binding protein-vitamin A complex in the serum and cerebrospinal fluid..$^{9-11}$ Dissociation of tetramic TTR and partial monomer unfolding is required for amyloid fibril formation. ${ }^{4,12}$ TTR fibril formation leads to the diseases senile systemic amyloidosis (SSA), familial amyloid polyneuropathy (FAP), and familial amyloid cardiomyopathy (FAC). The amyloid fibrils deposited in patients with SSA comprise exclusively wild-type (WT) TTR, while the fibrils found in patients with FAP and FAC are made up primarily of variant TTR. ${ }^{13-15}$ SSA affects, to some extent, $25 \%$ of the population over 80 years of age, and primarily involves deposition of amyloid in the heart resulting in congestive heart failure. ${ }^{16,17}$ With FAP, peripheral nerve involvement is prominent, whereas with FAC, cardiac involvement is prominent. ${ }^{18}$ More than 80 single site variants of TTR lead to FAP or FAC, ${ }^{19,20}$ however, only a few of the TTR variants lead to the majority of FAP and FAC cases based on the literature. ${ }^{17,19-21}$ These include V30M, V122I, T60A, L58H, and I84S. Details such as age of onset, 
disease course, locale, and cases reported by these common TTR variants are described in Table 1.

Several structurally distinct classes of small molecule TTR amyloid inhibitors have been discovered through screening or elaborated through structure-based design. ${ }^{23-26}$ These inhibitors function by binding one or both of the two equivalent thyroxine $\left(\mathrm{T}_{4}\right)$ sites at the TTR quarternary structure interface. Binding to the largely unoccupied ( $>95 \%$ ) $\mathrm{T}_{4}$ sites stabilizes the native state of TTR to an extent proportional to the binding affinity. Native state stabilization substantially raises the barrier for the TTR dissociation, which is the typical rate-limiting step of TTR amyloidogenesis. ${ }^{23,24,26,27}$ The structures of the inhibitors utilized in this study, along with their corresponding dissociation constants, maximum therapeutic serum levels, and human plasma binding stoichiometries are summarized in Table $2 .^{23,28-30}$ Diclofenac, diflunisal, and flufenamic acid are all nonsteroidal antiinflammatory drugs (NSAIDs). The first two are Food and Drug Administration (FDA) approved. Diclofenac is a modest fibril formation inhibitor in vitro against WT and V30M TTR. ${ }^{25}$ Moreover, its low maximum therapeutic level and low binding stoichiometry with TTR in human plasma limits its usefulness clinically (Table 2). Diflunisal is a better fibril formation inhibitor relative to diclofenac against WT TTR. ${ }^{23}$ Diflunisal has also been shown to have a binding stoichiometry exceeding 1.5 to serum TTR when given orally to human subjects at its recommended dosage (Sekijima Y., unpublished data). Flufenamic acid is slightly better at inhibiting WT TTR fibril formation in comparison to diflunisal. ${ }^{28}$

Table 1 Common TTR amyloidosis characteristics

\begin{tabular}{|c|c|c|c|c|}
\hline$T T R$ & Age of onset & Disease course & Location & $\begin{array}{l}\text { Cases } \\
\text { published }\end{array}$ \\
\hline $\mathrm{WT}$ & 80 & Late-onset cardiac involvement & Worldwide & $\begin{array}{l}25 \% \text { of people } \\
\text { over age } 80^{\mathrm{a}}\end{array}$ \\
\hline V30M & $30-60$ & $\begin{array}{l}\text { Presents with polyneuropathy and autonomic } \\
\text { dysfunction, then systemic involement (heart, } \\
\text { gastrointestinal tract etc) }\end{array}$ & Worldwide & $>400$ \\
\hline V122I & $60 \mathrm{~s}$ & Late-onset cardiac amyloidosis & African-American & $\begin{array}{l}\text { Most common } \\
\text { variant }^{\mathrm{b}}\end{array}$ \\
\hline T60A & $50 \mathrm{~s}$ & $\begin{array}{l}\text { Late-onset cardiac amyloidosis with some } \\
\text { neurologic involvement }\end{array}$ & Appalachian, Ireland & $>40$ \\
\hline $\mathrm{L} 58 \mathrm{H}$ & $40 \mathrm{~s}$ & $\begin{array}{l}\text { Usually presents with CTS and is slowly } \\
\text { progressive over two decades }\end{array}$ & Maryland, German & $>50$ \\
\hline I84S & $20-30$ & $\begin{array}{l}\text { CTS at } 30 \text {, vitreous opacities } 40-50 \text { s, then heart } \\
\text { involvement }\end{array}$ & Indiana, Switzerland & $>30$ \\
\hline
\end{tabular}

CTS $=$ carpal tunnel syndrome.

${ }^{\mathrm{a}}$ Leads to SSA. Considering the population over 80, $25 \%$ were found to have cardiac involvement on autopsy. ${ }^{16}$ The number of patients with cardiac amyloid deposition that develop clinically significant disease (SSA) is not entirely clear.

${ }^{\mathrm{b}}$ Approximately $3.9 \%$ of African Americans (1.3 million) are heterozygous for this variant. ${ }^{22}$

Table 2 Structures and properties of selected TTR amyloidogenesis inhibitors

\begin{tabular}{|c|c|c|c|c|c|c|}
\hline & \multicolumn{2}{|c|}{$W T$} & \multicolumn{2}{|c|}{ V30M } & \multirow{2}{*}{$\begin{array}{c}\text { Maximum } \\
\text { therapeutic } \\
\text { concentration }(\mu M)\end{array}$} & \multirow{2}{*}{$\begin{array}{c}\text { Molar equivalent } \\
\text { bound to human } \\
\text { plasma TTR at } \\
10.8 \mu M^{\mathrm{a}}\end{array}$} \\
\hline & $\mathrm{K}_{d 1}(n M)$ & $\mathrm{K}_{d 2}$ & $\mathrm{~K}_{d 1}(n M)$ & $\mathrm{K}_{d 2}$ & & \\
\hline Diclofenac & 60 & $1.2 \mu \mathrm{M}$ & 160 & $3.9 \mu \mathrm{M}$ & 5 & 0.04 \\
\hline Diflunisal & 75 & $1.1 \mu \mathrm{M}$ & - & - & 400 & 0.13 \\
\hline $\begin{array}{l}\text { Flufenamic } \\
\text { acid }\end{array}$ & 30 & $225 \mathrm{nM}$ & 41 & $320 \mathrm{nM}$ & 54 & 0.20 \\
\hline Inhibitor $\mathbf{1}^{\mathrm{b}}$ & 5 & $5 \mathrm{nM}$ & - & - & - & 1.38 \\
\hline
\end{tabular}

${ }_{\mathrm{b}}^{\mathrm{a}}$ Range is from 0 to 2 , representing the extent of occupancy of the two binding sites available on each TTR tetramer.

$\mathrm{b}_{2-[(3,5-\text { dichlorophenyl) amino] benzoic acid. }}$ 
Flufenamic acid is a commonly used NSAID outside USA, but it is not FDA approved. Flufenamic acid has increased binding affinity as well as increased plasma selectivity for WT TTR as compared to diclofenac and diflunisal (Table 2). The diclofenacanalog inhibitor 1 (2-[(3,5-dichlorophenyl) amino] benzoic acid) was synthesized based on structurebased drug design suggestions. ${ }^{25}$ Inhibitor 1 has the highest binding affinity (Table 2) and inhibitor efficacy against WT TTR amyloidogenesis, ${ }^{25}$ however, it is not an approved drug and its safety is unknown.

Here we explored the ability of the above inhibitors to stabilize the most common TTR variant homotetramers against amyloidogenesis mediated by partial acid denaturation in vitro and against dissociation mediated by urea denaturation. Our results show that the strategy of utilizing small molecule inhibitors to stabilize TTR against amyloidogenesis can be extended to the majority of common variants associated with FAP and FAC. These results provide incentive to continue developing compounds for clinical trials. We also set out to identify the most effective inhibitors as well as to investigate whether the altered kinetic and thermodynamic parameters of the TTR variants predict the relative efficacy of the inhibitors against these variants.

\section{Materials and methods}

\section{Protein Expression and Purification}

The V30M, T60A, L58H, I84S, and V122I plasmids were prepared utilizing the QuickChange sitedirected mutagenesis procedure from Stratagene (La Jolla, CA, USA) using WT TTR DNA as the template. Mutations were verified by DNA sequencing. Recombinant WT TTR and variants were expressed in BL21/DE3 Epicurean gold Escherichia coli transformed with $\mathrm{pmmH} \alpha$ plasmids containing the TTR and ampicillin-resistance genes. Expression and purification were performed as described in detail previously. ${ }^{31}$ Protein identification was verified through mass spectrometry.

\section{Urea-Mediated Unfolding of TTR (T60A, L58H, I84S)} Measured by Tryptophan Fluorescence

Samples containing TTR $(0.1 \mathrm{mg} / \mathrm{ml})$ were incubated $\left(25^{\circ} \mathrm{C}\right)$ at various concentrations of urea in $50 \mathrm{mM}$ phosphate buffer (pH 7.0; $100 \mathrm{mM} \mathrm{KCl,} 1$ mM EDTA, $1 \mathrm{mM}$ DTT) for $96 \mathrm{~h}$. Urea solutions were checked by refractive index to verify the concentration prepared by weight. All TTR Trp fluorescence spectra were recorded over the range of 310 to $410 \mathrm{~nm}$ with excitation at $295 \mathrm{~nm}$. The fluorescence ratio at 355 and $335 \mathrm{~nm}$ was used as a structural probe as described previously. ${ }^{32}$
Fibril Formation Assay of TTR Variants with Small Molecule Inhibitors

Inhibitors diclofenac, diflunisal, flufenamic acid, and inhibitor 1 were each dissolved in DMSO stock solutions of $7.2,14.4$, and $21.6 \mathrm{mM}$. Then $0.5 \mu \mathrm{l}$ of each stock solution was added to $500 \mu \mathrm{l}$ of each TTR variant stock solution $(7.2 \mu \mathrm{M}$ in $10 \mathrm{mM}$ sodium phosphate, $100 \mathrm{mM} \mathrm{KCl}, 1 \mathrm{mM}$ EDTA, $1 \mathrm{mM}$ DTT (pH 7)) to achieve inhibitor concentrations of 7.2 , 14.4 , and $21.6 \mu \mathrm{M}$, respectively. DMSO $(0.5 \mu \mathrm{l})$ was added to $500 \mu \mathrm{l}$ of each TTR variant to serve as a control in samples without inhibitor. These samples were incubated for $3 \mathrm{~h}$ and then they were diluted 1:1 with $100 \mathrm{mM}$ acidification buffer $(100 \mathrm{mM})$ containing $100 \mathrm{mM} \mathrm{KCl}, 1 \mathrm{mM}$ EDTA, and $1 \mathrm{mM}$ DTT. Citrate buffer was used when a final $\mathrm{pH} \leq 3.8$ was desired; acetate buffer was used for the $\mathrm{pH}$ range of 4.1-5.8; and phosphate buffer was utilized for $\mathrm{pH}$ from 6.2 to 6.8. Samples were incubated at $37^{\circ} \mathrm{C}$ for $72 \mathrm{~h}$ without stirring after acidification. Fibril formation was then quantified by determining the turbidity of the solution at $400 \mathrm{~nm}$ after vortexing the sample for $5 \mathrm{~s}$. The $\mathrm{pH}$ of maximum fibril formation for each TTR variant was determined, and the amount of fibril formation without inhibitor was defined as 1.0.

\section{Rate of Tetramer Dissociation of TTR Variants with Small Molecule Inhibitors as Measured by Circular Dichroism Spectroscopy}

Inhibitors diclofenac, diflunisal, flufenamic acid, and inhibitor 1 were suspended in ethanol stock solutions of $9 \mathrm{mM}$. Inhibitor stock solutions $(2,4$, and $6 \mu \mathrm{l}$ ) were added to $1 \mathrm{ml}$ of each TTR variant stock solution $(1 \mathrm{mg} / \mathrm{ml}$ in $50 \mathrm{mM}$ sodium phosphate, $100 \mathrm{mM} \mathrm{KCl}, 1 \mathrm{mM}$ EDTA, $1 \mathrm{mM}$ DTT (pH 7)) in Eppendorfs. Ethanol $(4 \mu \mathrm{l})$ was added to $1 \mathrm{ml}$ of each variant TTR stock to serve as control without inhibitor. The samples were incubated for $6 \mathrm{~h}$ at $25^{\circ} \mathrm{C}$ and then $400 \mu \mathrm{l}$ was transferred to a $2 \mathrm{ml}$ tube. Then $1300 \mu \mathrm{l}$ of $10 \mathrm{M}$ urea $(50 \mathrm{mM}$ sodium phosphate, $100 \mathrm{mM} \mathrm{KCl,} 1 \mathrm{mM}$ DTT (pH 7)) and $300 \mu \mathrm{l}$ buffer $(50 \mathrm{mM}$ sodium phosphate, $100 \mathrm{mM} \mathrm{KCl}$, $1 \mathrm{mM}$ DTT ( $\mathrm{pH} 7)$ ) were added to $2 \mathrm{ml}$ tube for a final urea concentration of $6.5 \mathrm{M}$ and a final TTR concentration of $3.6 \mu \mathrm{M}$. The $2 \mathrm{ml}$ samples were vortexed and then far-UV CD spectra $(210-220 \mathrm{~nm})$ were measured intermittently up to approximately $200 \mathrm{~h}$ at $25^{\circ} \mathrm{C}$. The slow dissociation rate was measured by linking it to fast tertiary structural changes. ${ }^{33}$

\section{Results}

Relative Thermodynamic and Kinetic Stability of the TTR Variants

TTR structural stability can be ascertained by $\operatorname{Trp}$ fluorescence-monitored urea denaturation curves. ${ }^{33}$ 
Despite significant efforts, it has proven very difficult to extract thermodynamic parameters from these data because the quarternary and tertiary structural transitions are linked. Nonetheless, the structural stability of the familial variants studied herein can be rank ordered to assess whether homotetramer stability is related to the relative effectiveness of a given small molecule inhibitor. Urea denaturation mid points $\left(C_{m}\right)$ can be used for this purpose provided the $m$-values, the sensitivity of the various homotetramers to urea denaturation, are similar. The urea denaturation curves of the TTR variants used in this study that were not reported previously (T60A, L58H, and I84S) are shown in Figure 1. The $C_{m}$ 's of the urea denaturation curves of $\mathrm{T} 60 \mathrm{~A}, \mathrm{~L} 58 \mathrm{H}$, and I84S were 2.8, 2.3, and 2.4, respectively (Table 3 ). The $C_{m}$ 's for WT, V122I, and V30M have been determined prior to this study ${ }^{33}$ and were $3.4,3.4$, and 2.0 , respectively (Table 3). These data indicate that all common TTR variants,

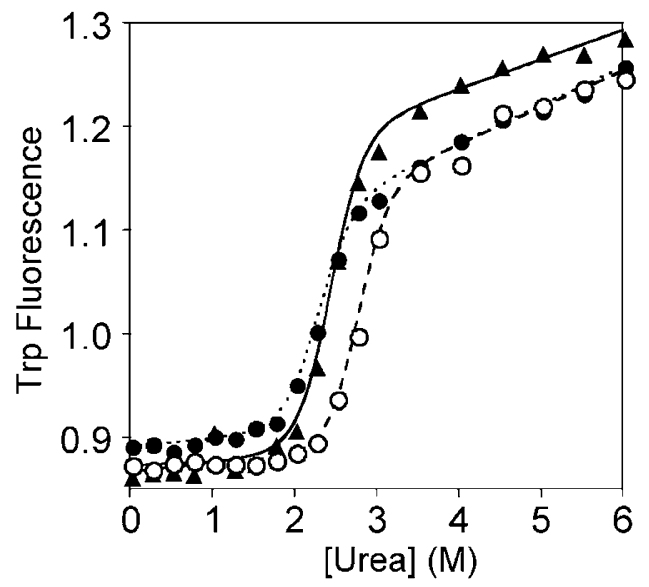

Figure 1 Evaluation of the thermodynamic stability of TTR sequences as a function of urea concentration; I84S $(\boldsymbol{\Lambda}), \mathrm{L} 58 \mathrm{H}$ $(\bullet)$, T60A $(\bigcirc)$. Urea unfolding curve measured by intrinsic tryptophan fluorescence changes reflecting linked tetramer dissociation and monomer unfolding.

Table 3 Kinetic and thermodynamic stability of familial disease variants

\begin{tabular}{lcc}
\hline $\begin{array}{l}\text { TTR } \\
\text { sequence }\end{array}$ & $\begin{array}{c}\text { Urea denaturation } \\
\text { midpoint }\left(C_{m}\right)^{\mathrm{a}}\end{array}$ & $\begin{array}{c}\mathrm{t}_{1 / 2} \text { for tetramer } \\
\text { dissociation in } 6.5 \mathrm{M} \\
\text { urea }(h)^{\mathrm{b}}\end{array}$ \\
\hline WT & 3.4 & $15.4(14.4-16.5)$ \\
V30M & 2.0 & $11.8(11.2-12.5)$ \\
V122I & 3.4 & $6.9(6.5-7.4)$ \\
T60A & 2.8 & $10.5(9.9-11.2)$ \\
L58H & 2.3 & $10.5(10.0-11.0)$ \\
I84S & 2.4 & $11.2(10.5-11.9)$
\end{tabular}

${ }^{\mathrm{a}}$ The $C_{m}$ of each variant homotetramer reflects the stability of the tetramer and the monomeric tertiary structure as these equilibria are linked.

${ }^{\mathrm{b}}$ The $t_{1 / 2}$ reported is that of tetramer dissociation in $6.5 \mathrm{M}$ urea with a range to take into account the error inherent in fitting to a first order single exponential function. with the exception of V122I, are less stable than WT towards urea denaturation. Urea will not directly denature a TTR tetramer; dissociation to monomer is required to observe denaturation. The half-life for tetramer dissociation was determined by linking the slow process of dissociation to the rapid tertiary structural changes easily monitored by circular dichroism spectroscopy in $6.5 \mathrm{M}$ urea. ${ }^{33}$ These experiments yielded half-lives for WT, V30M, V122I, T60A, $\mathrm{L} 58 \mathrm{H}$, and I84S TTR of $15.4,11.8,6.9,10.5,10.5$, and $11.2 \mathrm{~h}$, respectively (Figure 2, Table 3). These data indicate that all common TTR mutants dissociate faster than WT TTR $(0.2 \mathrm{mg} / \mathrm{ml})$ in $6.5 \mathrm{M}$ urea.

\section{Influence of Inhibitors on Fibril Formation of Common TTR Variants}

The extent of variant TTR amyloid fibril formation as a function of $\mathrm{pH}$ and inhibitor concentration was evaluated by measuring turbidity at $400 \mathrm{~nm}$ after $72 \mathrm{~h}$ of incubation. The TTR concentration employed $(3.6 \mu \mathrm{M})$ is the average physiologic concentration, while the inhibitors were evaluated at 3.6, 7.2, and $10.8 \mu \mathrm{M}$ concentrations. In this study, the efficacy of inhibition for each variant homotetramer was measured under conditions (pHs) optimal for maximal TTR fibril formation. The results are shown in Figure 3 . The inhibitors used in this study were effective at reducing fibril formation below $10 \%$ of that exhibited by the positive control when employed at a concentration of $7.2 \mu \mathrm{M}$, with the exception of diclofenac, which did not achieve this efficacy for V122I, T60A, or I84S TTR. The difference between the inhibitors was more clearly revealed when employed at a concentration equal to that of TTR $(3.6 \mu \mathrm{M})$. The order of efficacy of the compounds against amyloidogenesis was the same for all variants: inhibitor $\mathbf{1}$ was superior, followed by flufenamic acid, then diflunisal, and, lastly, diclofenac.

\section{Influence of Inhibitors on Rate of Variant TTR Homotetramer Dissociation}

Tetramer dissociation rates were measured by linking slow quarternary structural changes to rapid tertiary structural changes by a method described previously. ${ }^{32,33}$ Tertiary structural changes were measured by circular dichroism in $6.5 \mathrm{M}$ urea. These conditions prevent subunit refolding and render the unfolding process irreversible. The TTR concentration was $3.6 \mu \mathrm{M}$, while the inhibitors were evaluated at 3.6, 7.2, and $10.8 \mu \mathrm{M}$ concentrations. Variant TTR dissociation rates as a function of diclofenac, diflunisal, flufenamic acid, and inhibitor 1 (Figure 2) reveal differential dose-dependent slowing. Diclofenac slowed the WT TTR tetramer dissociation rate more than that of the variants. The most prominent loss of efficacy was with V30M, where the presence of diclofenac had little impact on the dissociation rate. This is partially explained by the 
WT
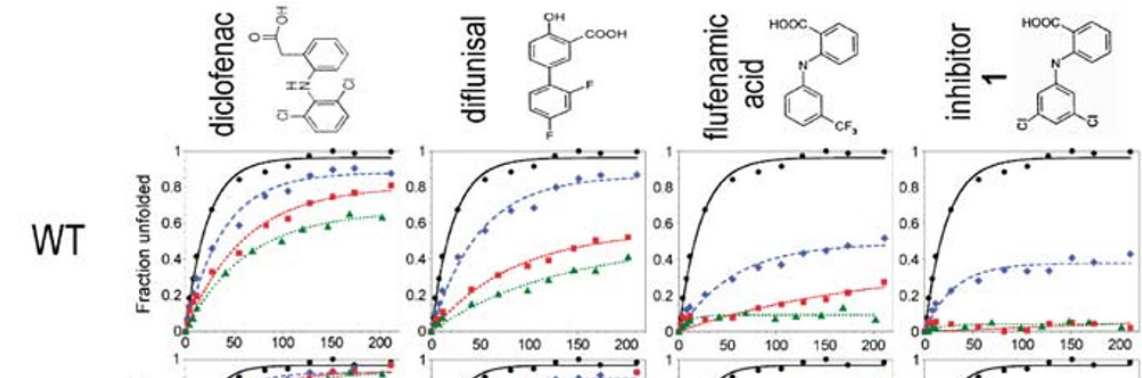

V30M
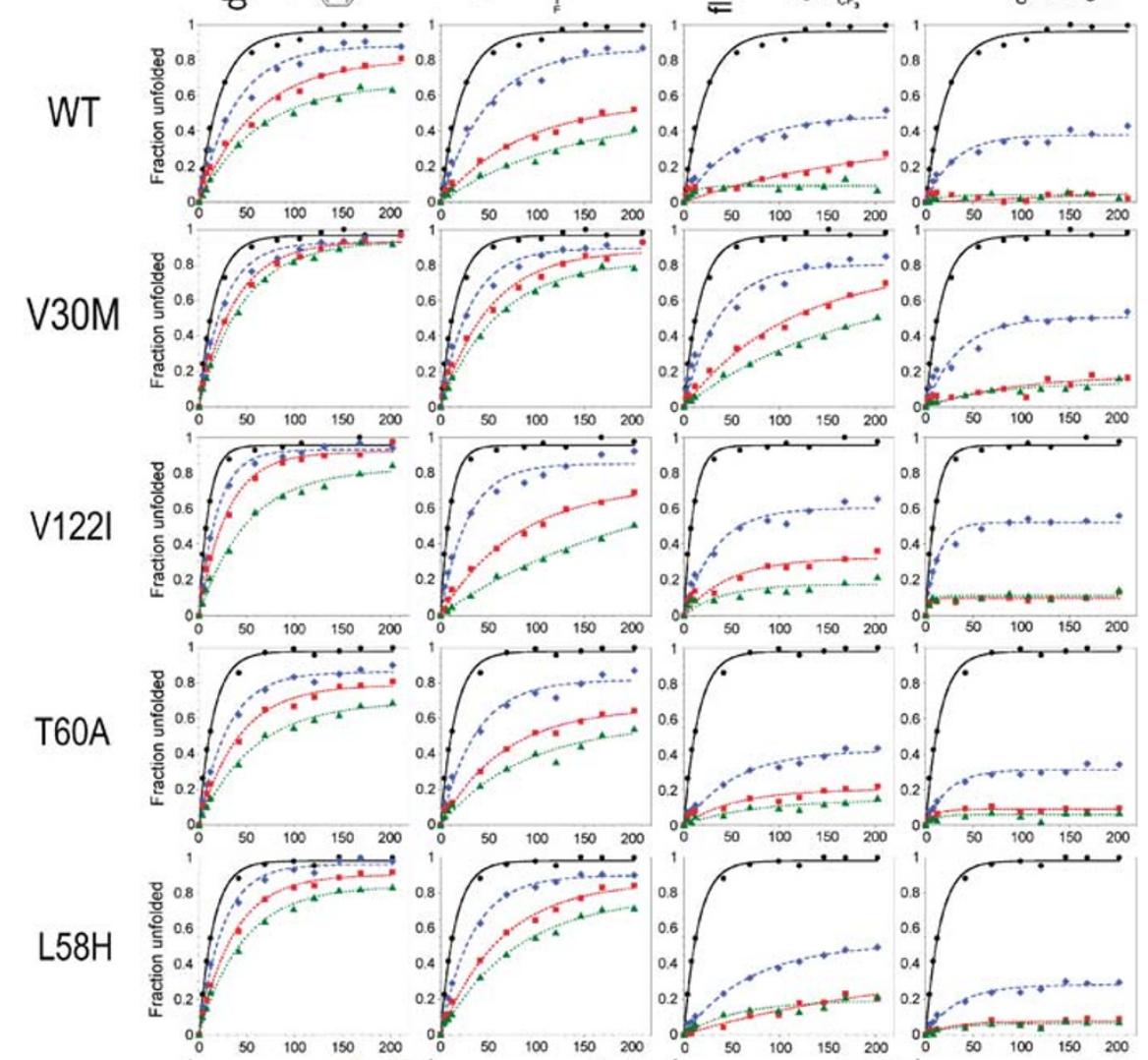

$184 \mathrm{~S}$
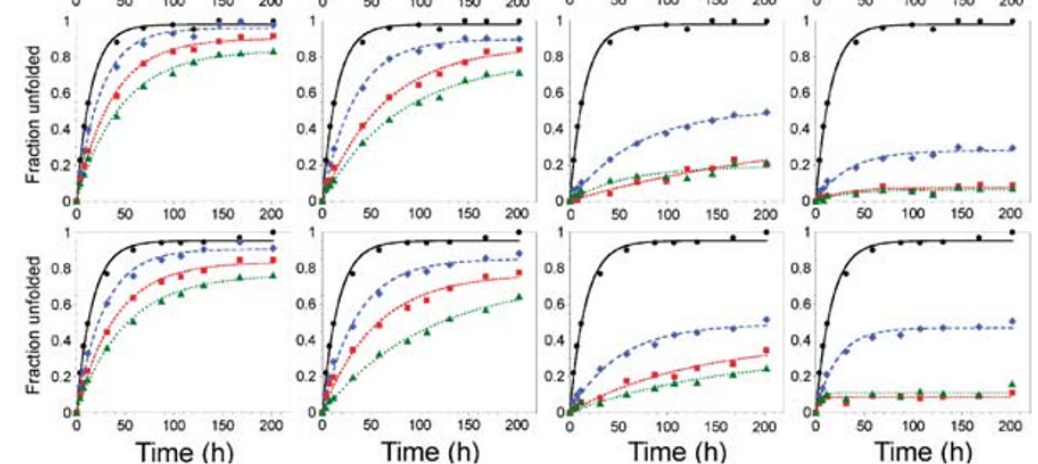

Figure 2 Influence of small molecule inhibitors $(0 \mu \mathrm{M}(\bullet), 3.6 \mu \mathrm{M}(\bullet), 7.2 \mu \mathrm{M}(\square), 10.8 \mu \mathrm{M}(\Delta))$ on the rate of WT and variant tetramer $(3.6 \mu \mathrm{M})$ dissociation in $6.5 \mathrm{M}$ urea measured by far-ultraviolet circular dichroism. Inhibitors tested include diclofenac, diflunisal, flufenamic acid, and inhibitor 1. Lines are fitted to a first order single exponential function.

decreased binding affinity of diclofenac to V30M (Table 2). The only TTR variant whose dissociation was slowed to the same extent as WT was T60A. Diflunisal was more effective at inhibiting tetramer dissociation across the spectrum of TTR variants than was diclofenac. Why diflunisal is more effective than diclofenac at slowing WT TTR dissociation may be related to their binding affinities in urea, which may not be accurately reflected by the binding constants measured in physiologic buffers (Table 2). The efficacy of inhibition by diflunisal is diminished proportional to variant TTR homotetramer instability (Table 3). Diflunisal, accordingly, lost significant activity against V30M, which is the most destabilized TTR variant employed in this study.

Flufenamic acid exhibited even greater slowing of dissociation tetramer. Even at concentrations of
3.6-7.2 $\mu \mathrm{M}$, flufenamic acid was equivalent to or more effective than diflunisal at a concentration of $10.8 \mu \mathrm{M}$ across the spectrum of variants. This is likely explained by its higher affinity to WT TTR relative to diflunisal (Table 2). Flufenamic acid substantially slowed the dissociation rates of all the familial TTR variants, similar to its effect on WT TTR. Again, this compound was least effective against the most destabilized variant V30M. Less than $20 \%$ of the variant tetramers (not including V30M) dissociated after $200 \mathrm{~h}$ when flufenamic acid was utilized at a concentration of $10.8 \mu \mathrm{M}$.

In this group of compounds, inhibitor $\mathbf{1}$ was superior at slowing the rate of tetramer dissociation in a dose-dependent manner. In fact, this compound may be more active against some TTR variants than WT TTR. Tetramer dissociation was slowed dramatically with inhibitor 1 at a concentration of 7.2 or 

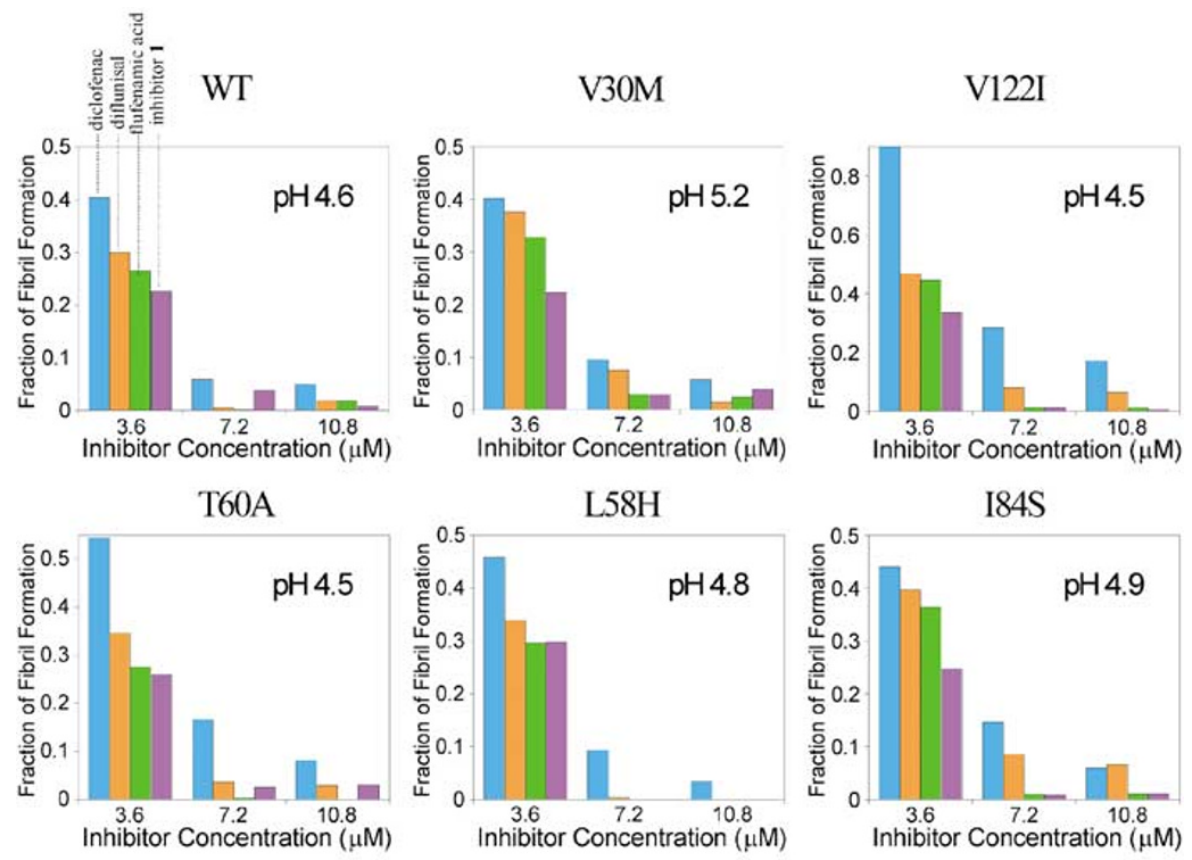

Figure 3 Small molecule inhibition of WT and variant TTR amyloid fibril formation. Inhibition of WT and the variant TTR (3.6 $\mu$ M) fibril formation by diclofenac $(\square)$, diflunisal $(\square)$, flufenamic acid $(\square)$, and inhibitor $1(\square)$ at the pH of maximum fibril formation for each TTR homotetramer (depicted on each graph) as a function of inhibitor concentration as evaluated by turbidity at $400 \mathrm{~nm}\left(\mathrm{OD}^{400}\right)$ after $72 \mathrm{~h}$. The amount of fibril formation is recorded as a fraction of fibril formation relative to the amount produced without inhibitor.

$10.8 \mu \mathrm{M}$ across all TTR variants studied. In summary, the rank ordering of compounds that slow TTR tetramer dissociation is inhibitor $\mathbf{1}$, flufenamic acid, diflunisal, and then, finally, diclofenac.

\section{Discussion}

TTR amyloid fibril formation requires rate-limiting tetramer dissociation followed by a rapid conformational change in the monomer that enables monomer misassembly. The small molecule inhibitors bind TTR and stabilize the native tetramer by an amount proportional to their binding constants. ${ }^{23}$ Selective stabilization of the ground state relative to the dissociative transition state can substantially slow tetramer dissociation as well. The kinetic stabilization mechanism utilized by the inclusion of T119M trans-suppressor subunits into tetramers otherwise composed of V30M subunits is known to ameliorate familial amyloid polyneuropathy, ${ }^{23,34,35}$ making it likely that small molecule stabilization will be effective in humans. Liver transplantation is an effective means of replacing variant TTR with WT TTR in patients with TTR familial amyloidosis, ${ }^{36}$ often ameliorating disease. Liver transplantation has many associated drawbacks, including the invasiveness of the procedure and the resultant immunocompromised state of the patient. Many patients with familial amyloidosis also have other organs affected that prevent them from being liver transplant candidates.
Small molecule inhibitors offer a potential alternative for treatment of patients with familial amyloidosis, which is practical, inexpensive, and noninvasive. While more than 80 TTR variants cause familial amyloidosis, fortunately, only a few mutations lead to the majority of cases of familial amyloidosis (V30M, V122I, T60A, L58H, and I84S). The results of this study show that small molecule inhibitors of acid-induced fibril formation and ureainduced tetramer dissociation previously demonstrated to be efficacious against WT TTR are also effective against the common familial TTR variants, especially inhibitor $\mathbf{1}$ and flufenamic acid. In this paper, we employed homotetramers of variant TTR. At present, nine FAP families homozygous for V30M TTR have been reported. ${ }^{37-42}$ All the homozygotes are members of families characterized by incomplete FAP penetrance. A comparison of the ages of disease onset reveals that homozygotes present slightly earlier than heterozygotes within the same family. This is compatible with our previous biophysical data, showing that amyloidogenicity slightly decreases with increasing WT subunit stoichiometry in the following order: $(\mathrm{V} 30 \mathrm{M})_{4}>(\mathrm{V} 30 \mathrm{M})_{3}$ $\mathrm{WT}>(\mathrm{V} 30 \mathrm{M})_{2}(\mathrm{WT})_{2}>\mathrm{V} 30 \mathrm{M}(\mathrm{WT})_{3}>(\mathrm{WT})_{4} \cdot{ }^{35}$ Since small molecules stabilize and inhibit amyloidogenesis of homotetramers comprising FAP subunits and homotetramers of WT subunits, small molecules should also be effective against amyloidogenesis from heterotetramers that are found in patients' serum composed of WT and/or FAP subunits. 
Diclofenac performed poorly at both inhibiting acid-induced fibril formation and slowing ureainduced tetramer dissociation of the familial variants. These results, in combination with diclofenac's low plasma selectivity and low maximum serum concentration (Table 2), make it a poor candidate for clinical trials. Diflunisal showed good inhibition of both fibril formation and tetramer dissociation for the majority of variants. The efficacy of diflunisal as an inhibitor of tetramer dissociation in this study was directly related to the thermodynamic stability (Table 3) of the TTR variant homotetramers. The decrease in diflunisal activity against V30M dissociation can be compensated for by its very high plasma concentrations (Table 2). A multicenter study investigating the use of diflunisal in the treatment of SSA, FAP, and FAC will soon begin.

Flufenamic acid performed a little better than diflunisal as an acid-mediated fibril formation inhibitor and much better as an inhibitor of ureainduced tetramer dissociation. Since we do not know where or how fibril formation occurs in vivo, compounds that perform well under a variety of denaturation conditions are sought. Flufenamic acid's efficacy at slowing urea-induced TTR tetramer dissociation may be the result of several factors incuding a higher affinity for tetrameric TTR in this denaturant. It is important to point out that inhibitors are typically better at preventing acidinduced fibril formation than at slowing ureainduced dissociation because the former requires misassembly of the monomeric amyloidogenic intermediate to get a signal, while the latter does not. Therefore, as long as the monomeric amyloidogenic intermediate is kept below its critical concentration, no fibril formation will occur. ${ }^{23}$ Flufenamic acid is expected to be superior to diflunisal on account of its significantly lower dissociation constants (Table 2). It is also possible that the dissociation constants for diflunisal and flufenamic acid are altered in acidic conditions or urea-denaturing conditions making performance better or worse than that would be expected based on $K_{d 1}$ and $K_{d 2}$ determined under physiologic conditions. ${ }^{23}$ Flufenamic acid's plasma selectivity is also better than diflunisal's. ${ }^{29}$ The shortcomings of flufenamic acid include its lower maximum therapeutic serum level (Table 2) and the fact that it is an approved drug only outside the United States.

Inhibitor $\mathbf{1}$ is superior as an acid-mediated fibril formation and urea-mediated tetramer dissociation inhibitor among this group. Its activity extends to all TTR variants with a paradoxical increase in inhibition towards tetramer dissociation with variants T60A and L58H. The efficacy of inhibitor 1 and other synthesized small molecules provides the incentive to further elaborate their structures for the treatment of SSA, FAC, and FAP. We are optimistic that small molecule inhibitors with appropriate pharmokinetic properties and minimal toxicity will be clinically useful based on their mechanistic analogies with interallelic trans-suppression, which is known to ameliorate pathology. ${ }^{23}$

\section{Acknowledgement}

We thank Luke Wiseman, Evan Powers, Brady Miller, Tammy Chen, and Jacob C Miller for helpful discussions. We gratefully acknowledge the National Institutes of Health (Grant DK-46335), The Skaggs Institute of Chemical Biology, and the Lita Annenberg Hazen Foundation for the financial support of this work.

\section{References}

1 Sipe JD. Amyloidosis. Annu Rev Biochem 1992; 61:947-975.

2 Sipe JD. Amyloidosis. Crit Rev Clin Lab Sci 1994; 31:325-354.

3 Tan SY, Pepys MB. Amyloidosis. Histopathology 1994;25:403-414.

4 Colon W, Kelly JW. Partial denaturation of transthyretin is sufficient for amyloid fibril formation in vitro. Biochemistry 1992;31:8654-8660.

5 Kelly JW. Alternative conformations of amyloidogenic proteins govern their behavior. Curr Opin Struct Biol 1996;6:11-17.

6 Kelly JW. Amyloid fibril formation and protein misassembly: a structural quest for insights into amyloid and prion diseases. Structure 1997;5:595-600.

7 Kelly JW. The alternative conformations of amyloidogenic proteins and their multi-step assembly pathways. Curr Opin Struct Biol 1998;8:101-106.

8 Lai Z, Colon W, Kelly JW. The acid-mediated denaturation pathway of transthyretin yields a conformational intermediate that can self-assemble into amyloid. Biochemistry 1996;35:6470-6482.

9 Bartalena L, Robbins J. Thyroid hormone transport proteins. Clin Lab Med 1993;13:583-598.

10 Blake CC, Geisow MJ, Oatley SJ, et al. Structure of prealbumin: secondary, tertiary and quarternary interactions determined by Fourier refinement at $1.8 \AA$. J Mol Biol 1978;121:339-356.

11 Monaco HL. The transthyretin-retinol-binding protein complex. Biochim Biophys Acta 2000;1482:65-72.

12 Jiang X, Smith CS, Petrassi HM. An engineered transthyretin monomer that is nonamyloidogenic, unless it is partially denatured. Biochemistry 2001; 40:11442-11452.

13 Cornwell III GC, Sletten K, Johansson B, Westermark P. Evidence that the amyloid fibril protein in senile systemic amyloidosis is derived from normal prealbumin. Biochem Biophys Res Commun 1988;154:648-653.

14 Saraiva MJ, Birken S, Costa PP, et al. Amyloid fibril protein in familial amyloidotic polyneuropathy, Portuguese type. J Clin Inv 1984;74:104-119.

15 Westermark P, Sletten K, Johansson B, et al. Fibril in senile systemic amyloidosis is derived from normal transthyretin. Proc Natl Acad Sci USA 1990;87: 2843-2845.

16 Cornwell III GG, Murdoch WL, Kyle RA, et al. Frequency and distribution of senile cardiovascular 
amyloid. A clinicopathologic correlation. Am J Med 1983;75:618-623.

17 Wallace MR, Dwulet FE, Conneally PM, et al. Biochemical and molecular genetic characterization of a new variant prealbumin associated with hereditary amyloidosis. J Clin Inv 1986;78:6-12.

18 Jacobson DR. Amyloidosis, transthyretin-related. E-Medicine. 2002; http://www.emedicine.com/med/ topic3365.htm.

19 Benson MD, Uemichi T. Transthyretin amyloidosis. Amyloid 1996;3:44-56.

20 Connors LH, Richardson AM, Théberge R, et al. Tabulation of transthyretin (TTR) variants as of $1 / 1$ / 2000. Amyloid 2000;7:54-69.

21 Nichols WC, Liepnieks JJ, McKusick VA, et al. Direct sequencing of the gene for Maryland/German familial amyloidotic polyneuropathy type II and genotyping by allele-specific enzymatic amplification. Genomics 1989;5:535-540.

22 Jacobson DR, et al. Variant-sequence transthyretin (isoleucine 122) in late-onset cardiac amyloidosis in black Americans. N Engl J Med 1997;336:466-473.

23 Hammarström P, Wiseman RL, Powers ET, et al. Prevention of transthyretin amyloid disease by changing protein misfolding energetics. Science 2003;299:713-716.

24 Klabunde T, Petrassi HM, Oza VB, et al. Rational design of potent human transthyretin amyloid disease inhibitors. Nat Struct Biol 2000;7:312-321.

25 Oza VB, Smith C, Raman P, et al. Synthesis, structure, and activity of diclofenac analogues as transthyretin amyloid fibril formation inhibitors. J Med Chem 2002;45:321-332.

26 Sacchettini JC, Kelly JW. Therapeutic strategies for human amyloid diseases. Nat Rev Drug Discov 2002;1:267-275.

27 Miroy GJ, Lai Z, Lashuel HA, et al. Inhibiting transthyretin amyloid fibril formation via protein stabilization. Proc Natl Acad Sci USA 1996;93: 15051-15056.

28 Peterson SA, Klabunde T, Lashuel HA, et al. Inhibiting transthyretin conformational changes that lead to amyloid fibril formation. Proc Natl Acad Sci USA 1998;95:12956-12960.

29 Purkey HE, Dorrell MI, Kelly JW. Evaluating the binding selectivity of transthyretin amyloid fibril inhibitors in blood plasma. Proc Natl Acad Sci USA 2001;98:5566-5571.

30 Steelman SL, Cirillo VJ, Tempero KF. The chemistry, pharmacology and clinical pharmacology of diflunisal. Curr Med Res Opin 1978;5:506-514.
31 Lashuel HA, Wurth C, Woo L, Kelly JW. The most pathogenic transthyretin variant, L55P, forms amyloid fibrils under acidic conditions and protofilaments under physiological conditions. Biochemistry 1999; 38:13560-13573.

32 Hammarström P, Jiang X, Deechongkit S, et al. Anion shielding of electrostatic repulsions in transthyretin modulates stability and amyloidosis: insight into the chaotrope unfolding dichotomy. Biochemistry 2001; 40:11453-11459.

33 Hammarström $\mathrm{P}$, Jiang X, Hurshman AR, et al. Sequence-dependent denaturation energetics: a major determinant in amyloid disease diversity. Proc Natl Acad Sci USA 2002;99:16427-16432.

34 Coelho T, Carvalho M, Saraiva MJ, et al. Familial amyloidotic polyneuropathy and other transthyretin related disorders. Second International Symposium. J Rheumatol 1993;20:179.

35 Hammarström P, Schneider F, Kelly JW. Trans-suppression of misfolding in an amyloid disease. Science 2001;293:2459-2462.

36 Skinner M, Lewis WD, Jones LA, et al. Liver transplantation as a treatment for familial amyloidotic polyneuropathy. Ann Intern Med 1994;120: 133-134.

37 Holmgren G, Haettner E, Nordenson I, et al. Homozygosity for the transthyretin-met30-gene in two Swedish sibs with familial amyloidotic polyneuropathy. Clin Genet 1988;34:333-338.

38 Sandgren O, Holmgren G, Lundgren E. Vitreous amyloidosis associated with homozygosity for the transthyretin methionine-30 gene. Arch Ophthalmol 1990;108:1584-1586.

39 Skare J, et al. Homozygosity for the met30 transthyretin gene in a Turkish kindred with familial amyloidotic polyneuropathy. Hum Genet 1990;86:89-90.

40 Holmgren G, et al. Homozygosity for the transthyretinMet30-gene in seven individuals with familial amyloidosis with polyneuropathy detected by restriction enzyme analysis of amplified genomic DNA sequences. Clin Genet 1992;41:39-41.

41 Yoshinaga T, Nakazato M, Ikeda S, et al. Homozygosity for the transthyretin-Met30 gene in three Japanese siblings with type I familial amyloidotic polyneuropathy. Neurology 1992;42:2045-2047.

42 Yoshioka A, et al. A case of familial amyloid polyneuropathy homozygous for the transthyretin Val30Met gene with motor-dominant sensorimotor polyneuropathy and unusual sural nerve pathological findings. Arch Neurol 2001;58:1914-1918. 